and lack of imagination at the Department of Health has restricted change to minor shifts in the proportions of senior and junior hospital staff and has maintained the status quo in general practice. Unpleasant, unpopular decisions have been avoided simply because migrant doctors and recent graduates have been available to plug the worst gaps in the service.

Given the constraints of the economic climate, there are only two possibilities for the future. If current policies and the present staffing structure of the NHS remain unchanged standards will undoubtedly continue to decline, morale will stay low, and we shall find that much of the NHS has become a second-class service with second-rate doctors. Already too few of the best recent graduates are embarking on postgraduate training programmes in Britain. ${ }^{4}$ A point of no return may soon be reached in some universities when the quality of the training offered begins to decline with the dearth of topquality trainees.

The other possibility requires recognition that, more than any other profession, medicine has to compete with every other country for talent. We cannot hope to retain first-rate doctors in Britain unless they are recognised as such and paid as a highly trained élite. Necessarily that means fewer doctors, doing only the sort of work that cannot be done just as well or better by someone else with a shorter training and lower salary expectations. Ancillaries and technicians must be given a greater role in the clinical services provided by the NHS, freeing doctors for demanding tasks requiring proper medical skills. Such a change would mean revising our attitudes, and not just in our medical schools: established clinicians may need to retrain to acquire new skills if some of their present work is to be handed over to non-medical staff. Perhaps the task of reshaping the Health Service to the needs and constraints of the 1980s will be left to the Royal Commission: but by then it may be too late. While any commission is sitting all proposals for reform tend to be shelved, so that unless this one is activated fast and asked to report quickly, it could delay change dangerously long. The problems are clear enough; there are possible solutions, but they need to be worked out soon if they are to be effective.

${ }_{1}$ British Medical fournal, 1964, 2, 1.

${ }^{2}$ British Medical fournal, 1976, $1,1$.

${ }^{3}$ British Medical fournal, 1976, 1, 56.

+ Smith, R, The Times, 9 October 1975.

\section{Cure for the corn?}

The corn is a hard and compact accumulation of the horny layers of the skin over a bony prominence of the foot. It is a common consequence of persistent frictional injury in men (or particularly women) who wear shoes. Corns are especially frequent in elderly individuals, in whom they often cause pain or difficulty in walking if they are not treated adequately. Doctors working with the elderly are often concerned at the general inadequacy of NHS chiropody services, though they see little prospect of early improvements.

The usual management of the corn is palliative, whether undertaken by a chiropodist or by the sufferer himself, and consists of either paring and padding to reduce further frictional trauma or using keratolytic paints or plasters. There has been little medical interest-as may be judged by the scanty cover of the subject in dermatology or geriatric text- books. Nevertheless, orthopaedic surgeons occasionally excise the underlying bony prominence in persistent and particularly troublesome corns, and this leads to cure in most cases. ${ }^{1}$ Balkin $^{2}$ has recently suggested an attractive alternative approach to radical treatment: to inject a cushion of a fluid silicone between the corn and the underlying bony prominence. This simple and non-disabling technique was free from complications and led to cure of the corn in two-thirds of cases and improvement in most of the remainder.

Further evaluation of this simple and potentially radical treatment appears to be warranted, for it might offer better relief to patients and reduce the load on overstretched chiropody services which continued palliative management imposes. Doctors might usefully take more interest in this common yet neglected problem.

\footnotetext{
${ }^{1}$ Du Vries' Surgery of the Foot, ed V T Inman. 3rd ed St Louis, Mosby, 1973.

${ }^{2}$ Balkin, S W, Archives of Dermatology, 1975, 111, 1143.
}

\section{Thyroid cancer}

Thyroid cancer is not a single disease but a group of conditions with different histological features, and understanding the clinicopathological interrelations is essential before planning treatment. At a recent symposium ${ }^{1}$ the excellent long-term survival in the differentiated tumours contrasted with the poor results in anaplastic cases; clearly, however, management would be improved if diagnosis and treatment were coordinated on a regional basis.

Many of the problems seen in the treatment of thyroid cancer stem from the clinician's failure to make an accurate diagnosis. A firm or hard mass with or without lymph node enlargement is highly suggestive of cancer, and should be classified $^{2}$ into one of three categories: obviously benign, cancer suspected, or cancer probable. Isotope scanning, needle aspiration cytology, and screening for thyroid autoantibodies are of little help in diagnosis, but the presence of microcalcification in a soft-tissue $x$-ray film of the gland is pathognomonic.

About $60 \%$ of all thyroid cancers are papillary tumours. This is the type that affects children and young women, but in older patients it becomes more aggressive and the survival time is low. Papillary tumours often present as cervical lymphadenopathy without an obvious mass in the thyroid gland, but there may be simply a firm goitre with no apparent extension to the lymph nodes. When the clinical diagnosis is suspected-either by the presence of an enlarged, often fluctuant node or a firm or hard mass in the thyroid glandthe neck should be explored and the node removed for immediate histological examination.

Authorities are not yet agreed on the ideal surgical treatment at this stage. Most centres advise a near total excision, preserving the parathyroids ${ }^{3-5}$; Crile $^{6}$ advocates conservative surgery; whereas $\mathrm{Clark}^{7}$ and Marshetta ${ }^{8}$ recommend routine total thyroidectomy because of the high incidence of microfoci of tumour in the "normal" lobe. The treatment of the lymph nodes is also in dispute. The number affected does not influence the survival time but the tumour will recur locally if they are not removed. Every attempt should be made at the initial operation to carry out a modified neck dissection "en bloc," with the thyroid gland and the nodes in continuity. The survival time is related to the patient's age and the stage of 